\title{
Aportaciones del catálogo gallego al apartado de Chistes y anécdotas de ATU
}

\author{
Camiño Noia Campos \\ Universidade de Vigo \\ cnoia@uvigo.es
}

\begin{abstract}
RESUMEN
De los 666 tipos y subtipos que componen el Catálogo tipolóxico do conto galego 43 subtipos llevan la marca Noia para clasificar aquellos cuentos que no están registrados en el ATU ni en el AT y que tampoco aparecen en los catálogos regionales de cuentos que consultamos. En este artículo me voy a referir exclusivamente a los 3 I clasificados con números Noia en el apartado de «Chistes y anécdotas» [Jokes and Anecdotes»] (I204*A-I95I*A), en general, piezas breves que todavía circulan en las comunidades rurales de Galicia y de otros territorios de la península ibérica. Analizo por qué se han eliminado algunos de estos números Noia y por qué se han mantenido 23 distribuidos en diversas secciones del apartado. Ocho relacionados con el ámbito eclesiástico que se refieren al comportamiento inadecuado de uno de sus miembros (obispo, papa, cura), la mayoría sobre la mala conducta de un cura lujurioso.
\end{abstract}

PALABRAS CLAVE

números de clasificación, chistes, versión, historia, anécdota

RESUM

Dels sis-cents seixanta-sis tipus i subtipus que composen el Catálogo tipolóxico do conto galego, 43 subtipus porten la marca Noia per classificar aquelles rondalles que no estan registrades a ATU ni a AT, i que tampoc apareixen en els catàlegs regionals de rondalles que consultem. En aquest article em referiré només als 3 I adscrits amb números Noia a la secció d' «Acudits i anècdotes» [ "Jokes and Anecdotes»] (I204*A-I95I*A), en general, peces breus que encara circulen en les comunitats rurals de Galícia i en altres territoris de la península ibèrica. Analitzo perquè s'han eliminat alguns d'aquests tipus Noia i per què se n'han mantingut vint-i-tres distribuïts en diverses seccions de l'apartat. Vuit estan relacionats amb l'àmbit eclesiàstic, i tenen com a motiu principal el comportament, gairebé sempre inadequat, d'un dels seus membres (bisbe, papa, capellà), la majoria referits a la conducta d'un capellà luxuriós.

PARAules ClaU

números de classificació, acudits, versió, història, anècdota 


\title{
Camiño Noia Campos
}

\begin{abstract}
Of the six hundred and sixty-six types and subtypes that make up the Catálogo tipolóxico do conto galego (Typological Catalogue of the Galician Folktale), fortythree subtypes are listed under the term Noia to classify those tales that are not registered in the ATU or the AT, and that also do not appear in the regional catalogues of folktales that we have consulted. In this paper I will refer only to the 3 I listed under the anecdotes and jokes section (I2O4*A-I95I*A), these being short pieces that still circulate in the rural communities of Galicia and other territories in the Iberian Peninsula. I analyze why I have removed some of these Noia numbers and why I have remained 23 types into various sections. Eight are related to the Church and the (always inappropriate) behaviour of one of its members (bishop, pope, priest). Most of them refer to lecherous priests.
\end{abstract}

KEYWORDS

classification numbers, jokes, version, history, anecdote 


\section{Introducción}

Es ya un tópico afirmar que AT, luego ATU, fue y sigue siendo un magnífico instrumento de organización y sistematización de la narrativa folclórica universal. A partir de AT hemos podido elaborar catálogos de narrativa folclórica en las diversas áreas lingüísticas de Occidente y de Oriente, otorgando a los cuentos orales, independientemente de la lengua en que se cuenten, un número de identidad. De esta manera, los cuentos del mundo se pueden relacionar con otras versiones extendidas por territorios muy alejados y es posible poner de manifiesto las variantes surgidas con el paso del tiempo en las distintas tradiciones.

Los catalogadores y las catalogadoras, mayoría en nuestro grupo, consideramos el ATU como nuestra biblia. En unos casos, fieles a su clasificación, no se han hecho nuevas propuestas ni se han recogido las que presentaban catálogos regionales; en otros, en cambio, sin salirnos del paraguas AT/ATU, nos servimos de catálogos regionales e, incluso, nos atrevemos a presentar nuevas propuestas de clasificación. En mi caso, y supongo que también en el de mis colegas Isabel Cardigos y Carlos González Sanz, lo hacemos con la voluntad de incluir en los catálogos todos los cuentos registrados en nuestras respectivas áreas lingüísticas para que puedan identificarse con un número de clasificación.

Con esa finalidad, en el Catálogo tipolóxico do conto galego de tradición oral (20IO), me atreví a dar un número (Noia) a todos aquellos cuentos orales de los que existían dos o más versiones y que no aparecían catalogados en ninguno de los índices conocidos. Es solo una propuesta provisional de clasificación, a la espera de que, detectadas otras versiones en las tradiciones de la península ibérica o fuera de ellas, se halle otra más adecuada o decidamos incluirlos en alguno de los tipos ATU.

Por eso quiero agradecer a Carme Oriol y Emili Samper, organizadores de la VII Trobada de treball GRENO, la elección del tema «Les formes breus de la narrativa oral», que nos han permitido debatir sobre nuestros cuentos breves, en particular sobre las anécdotas y los chistes (facécies, jokes), tan poco valorados por los informantes, e incluso por los folcloristas, y que en la actualidad son ya los únicos cuentos que se conservan en la memoria de las gentes.

En mi intervención en la Facultad de Letras de la Universitat Rovira i Virgili en octubre de 2012 hablé de los cuentos gallegos clasificados en el apartado «Chistes y anécdotas» (I2O4*A-I95I*A) con 3I números Noia; la mayor parte de ellos son piezas breves de las que todavía se pueden encontrar versiones en otras áreas lingüísticas de la península ibérica. Si entre los cuentos presentados incluí alguno que no cumple las características de lo que conocemos como «formas narrativas breves», fue con la intención de hablar de su clasificación para encontrar nuevas versiones en otras áreas lingüísticas.

El debate suscitado en el encuentro y las sugerencias posteriores de miembros de GRENO, y ajenos al grupo, me han llevado a pensar en la eliminación o el cambio de apartado de varios números Noia y a mantener otros en próximas edicio-

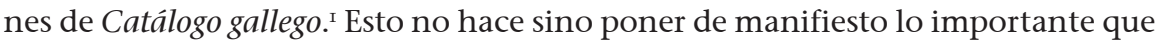

I. Es evidente que mientras haya ejemplares de la actual edición del Catálogo tipolóxico do conto galego de tradición oral no se hará una nueva edición gallega. Los cambios que se hagan se incluirán en la versión inglesa que preparamos. 
fue el encuentro para mí, pues, además de aprender de todas las comunicaciones presentadas, me permitió debatir mis propuestas de clasificación de chistes.

En el Catálogo tipolóxico do conto galego de tradición oral (CTCGTO) se clasifican 666 tipos y subtipos (números de clasificación). Veintiocho de ellos los he tomado del Catalogue of portuguese folktales (2006) de Isabel Cardigos y del Catálogo de contos tradicionais portugueses ${ }^{2}$ de Isabel Cardigos y Paulo Correia, todavía inédito, y ocho del Catálogo tipológico de cuentos folclóricos aragoneses (I996) de Carlos González Sanz, por citar solo los elaborados por investigadores vinculados a GRENO. Cuarenta y tres cuentos llevan la marca Noia. Como he señalado, son aquellos para los que no he encontrado clasificación en AT/ATU, ni en los catálogos regionales que he podido consultar, o que, estando clasificados, no me parecía adecuada su clasificación.

\section{Números provisionales}

Por las razones que explicaré a continuación, la inclusión de nueve números Noia $\left(\mathrm{I} 338^{*} \mathrm{C}, \mathrm{I} 338^{*} \mathrm{D}, \mathrm{I} 365^{*} \mathrm{~F}, \mathrm{I} 525^{*}\right.$, I545*B, I678*D, I73 ${ }^{*} \mathrm{~A}, \mathrm{I} 740^{*} \mathrm{C}$ y I848* $\mathrm{E}$ ) en el apartado de «Chistes e anécdotas» [«Jokes and Anecdotes»] del CTCGTO no me parece suficientemente justificada: en unos casos, porque existen tipos ATU en los que se podrían integrar los cuentos clasificados, y en otros, por considerar que no se trata de historias humorísticas.

El número $\mathrm{I} 338^{\star} \mathrm{C}$, «As visitas do Señor bispo (Papa)» [The visits of the Bishop (Pope)], clasifica siete chistes diferentes relacionados con visitas del Papa a una parroquia, a casa de un párroco, etc. Se habían recogido en aldeas de las provincias gallegas de Lugo, Ourense y Pontevedra, y dos versiones en el área lingüística del gallego de las provincias de Oviedo y León. Había incluido un nuevo número como una variante del I338B (CG), «Las comodidades del señor obispo», clasificado por Carlos González Sanz en el Catálogo de cuentos aragoneses (I996), pero una revisión posterior de las versiones incluidas en el número Noia me ha llevado a suprimirlo y a clasificar el conjunto de versiones gallegas en el tipo misceláneo ATU I694A A Foolish Welcome.

El I338*D (Noia) «Apostar por nada» [Betting for nothing] clasifica tres historias sobre apuestas con diferente intencionalidad y personajes. La historia más elaborada cuenta que un rico labrador promete sus dos bueyes a un campesino pobre, si es capaz de comer las dos grandes boñigas que acaban de cagar, confiando en que no lo hará. Cuando el pobre ya se ha comido una y observa la cara demudada del rico, le propone devolverle los bueyes si él se come la boñiga que falta. El rico se la come y todo se queda como estaba. Me parece una buena historia que necesita un número de identidad.

El I365*F y el I545*B no son, realmente, cuentos de humor, y deberán incluirse en otros apartados de ATU.

El I365*F, «Sen peixe non hai quentura» [No fish, no warming], relata cómo al regresar a casa un pescador muerto de frío la esposa lo sienta al lado del fuego para que pueda entrar en calor. Cuando este le dice que no ha pescado nada, ella lo aparta del fuego para que deje el sitio a los hijos.

2. Versión portuguesa del catálogo anterior, corregida y ampliamente aumentada, todavía inédita. Agradezco a sus autores, Isabel Cardigos y Paulo Correia, que me hayan permitido disponer de la versión digital. 
No me parece una historia didáctica, pues aunque el esposo es castigado por no cumplir su papel de cabeza de familia, no se nos dice la razón por la que llega sin salario. Por ello, la idea que extraemos es más bien de crueldad por parte de la esposa hacia su marido, que viene del mar aterido y sin haber podido pescar nada. Ciertamente no es un chiste, pero ¿en qué sección se podría clasificar?

El I545*B, «Escollendo xenro» [Choosing son-in-law], cuenta que el padre de una chica con varios pretendientes decide ponerlos a prueba para ver quién es el más adecuado. Les pide que hagan un objeto (una cuña, un torno) y escoge a aquel que le dice que no podrá hacer lo que le pide si no sabe dónde debe encajar la pieza.

La historia, más que un chiste, parece un cuento de intención didáctica; por eso he decidido clasificarlo en la sección Clever Acts and Words (920-929) con el número $92 \mathrm{IG}^{*}$ (Noia), dado que en ATU no hay cuentos con los mismos motivos.

El I525 $\mathrm{S}^{*}$, «Roubar por engano ao portador» [Stealing by deceit from the bearer], clasificado entre los cuentos de robos en Stories about a Man, no se puede considerar un cuento de risa, sino de engaño a un ignorante. Un párroco (u otra persona) pide a un hombre analfabeto que lleve el dinero de las bulas al obispado; de camino le salen al encuentro dos pillos que saben lo que lleva, le dicen que son gente del obispado y que ellos pueden llevar el dinero. El hombre se lo entrega a cambio de un papel firmado, y los pillos le dan un texto en el que se burlan de él. Cuando le reclaman el dinero al párroco, se descubre el engaño y el hombre tiene que restituir el dinero.

De esta historia se registran tres versiones, dos recogidas en la provincia de León, en territorio lingüísticamente gallego, y una en las proximidades de Tui, en la frontera con Portugal. Es, claramente, una historia realista que puede tener el origen en un suceso real.

El I678*D, «O paxaro esmagado» [The smashed bird], del que tengo dos versiones orales y una escrita, es una larga historia con varios episodios, para la cual no me parece adecuada la sección del «Hombre tonto» [The Stupid Man, I675-I724] donde había situado el número Noia.

a. Un chico se va a confesar con dos pájaros en el bolsillo. Mientras el sacerdote se dirige al penitente, los pájaros salen volando del bolsillo.

b. El chico deja la confesión y sale corriendo de la iglesia detrás de los pájaros ante el asombro del confesor, que lo llama para que vuelva.

c. En su carrera por perseguirlos el chico llega a una casa en la que se está bañando una muchacha que al verlo se tapa el pubis con las manos.

d. El chico confunde los pelos del pubis con las plumas de pájaro y recrimina a la muchacha por habérselo matado.

El elemento hilarante del cuento se centra en la confusión del pájaro con el pelo del pubis de la muchacha. El cuento, ciertamente, no es una forma breve. Su extensa estructura induce a pensar en la reescritura de un cuento oral sobre la confesión de un chico que ha robado pájaros de un nido, que se le escapan durante la confesión, con un final ingenioso e hilarante.

El I73I*A, «O amante vestido de muller déitase coa esposa infiel»[The lover dressed as a woman sleeps with the unfaithful wife], cuenta cómo la esposa engaña a su marido vistiendo al amante de mujer y haciendo creer a su esposo que es una prima (amiga, tía) que viene a visitarla y que quiere dormir con ella para poder 
hablar durante la noche. El marido descubre el engaño al ver los órganos sexuales al amante, y ante su protesta, la mujer vuelve a engañarlo con otro enredo.

En el Catálogo tipolóxico galego se registran cuatro versiones orales y una escrita, sin que haya referencias a versiones en otras áreas de la península. Aunque en las cuatro aparece el personaje del cura como amante, podría substituirse por un hombre sin mencionar la profesión, dado que la condición de clérigo no es un motivo esencial en la historia, centrada en la relación de la pareja. Por ello quizás debería pasar a la sección de «Cuentos sobre matrimonios» [Stories about married couples (I35O-I439)].

$\mathrm{El} \mathrm{I}_{74}{ }^{*} \mathrm{C}$, «Finxe ser unha ánima para sacar proveito» [Pretends to be a ghost to get profit of it], clasifica varios cuentos en los que una persona cubierta con una sábana blanca se hace pasar por el alma de un muerto que regresa al mundo terrenal para pedirle a su hermano (pariente, vecino o amigo) que reparta la herencia con él, que le venda una finca u otra cosa.

El problema para la clasificación de este tipo de historias reside en la trasmisión del o de la informante. En un tiempo no muy lejano, las historias relacionadas con la vuelta al mundo de las almas de los muertos se consideraban creencias sobre el más allá propias de la cultura religiosa de las comunidades campesinas, de ahí que Julio Camarena y Maxime Chevalier (2003a) las clasifiquen en el apartado de «Cuentos religiosos». En una época como esta en que la gente ha dejado de creer en las apariciones de los muertos, historias de este tipo ya no se pueden considerar creencias y deben incluirse más bien entre los cuentos de fantasmas. De ahí mi propuesta de clasificación. En cualquier caso, las historias presentadas tampoco se pueden clasificar entre los chistes, dado que en ellas no hay ningún tipo de hilaridad. Las versiones clasificadas con el número (Noia) tienen motivos coincidentes con ATU I74OB [Thieves as Ghosts] y con el 76oE (Cam-Che) [«Ánima en pena hasta la restitución de lo robado (o el cumplimiento de lo encargado)»]. Es necesario pues buscar un nuevo número que reúna las viejas creencias sobre aparecidos y estas historias para las que no hay una sección adecuada en ATU.

$\mathrm{El} 1848^{*} \mathrm{E}$, «O predicador desmedido» [The excessive preacher], clasifica dos versiones de una historia sobre un cura que hace sermones demasiado largos o muy trágicos; para evitarlo ata un cordel a uno de sus brazos y le pide al sacristán que tire de él si se sobrepasa en tiempo o incrementa los sufrimientos de Cristo. Cuando el sacristán tira del cordel, el cura corta el discurso y concluye diciendo una tontería o dice que, realmente, Cristo no sufrió nada.

El cuento se podría considerarse una variante del AT I848C (AT) Saint's Account Book, en la sección de «Other Jokes about Religious Figures», que fue suprimido de ATU, a pesar de su importante presencia en las áreas lingüísticas gallega, portuguesa y castellana. Otra opción es clasificar los cuentos con estos motivos en el tipo ATU I920D [The Liar Reduce The Size of His Lie] fuera del ámbito eclesiástico, que clasifica cuentos con el mismo tema: un mentiroso convulsivo le dice a un amigo que le pise los dedos de los pies cuando lo oiga mentir excesivamente; y cuando el amigo se los pisa, el mentiroso termina la historia reduciendo exageradamente la pequeñez de lo que estaba ampliando. ${ }^{3}$ A pesar de que todas las versiones incluidas en el número Noia tienen por personajes a un cura y un sacristán, el

3. «A liar agrees with his friend that the friend will step on his toes if he begins to lie excessively. When this happens it causes the liar to end his story with exaggerated smallness rather than largeness». 
resto de los motivos coinciden con los cuentos clasificados en ATU I920D; alargar o exagerar (mentir) para impresionar a los receptores, hay un cómplice (sacristán, amigo) que avisa y la reducción excesiva del objeto o de la historia previamente exagerada.

\section{Números consolidados}

De los 3 I números Noia del apartado «Chistes e anécdotas» [ «okes and Anecdotes»] incluidos en el CTCGTO, solo 23 son propuestas de clasificación consolidables, sin que eso signifique que no puedan aparecer nuevas propuestas que me lleven a cambiar su catalogación. Se trata de los números $\mathrm{I} 204^{*} \mathrm{~A}, \mathrm{I} 35^{*} \mathrm{~B}, \mathrm{I} 357^{*} \mathrm{~B}, \mathrm{I} 362 \mathrm{C}^{*}$, I380B ${ }^{*}, \mathrm{I}_{380 \mathrm{C}^{*},}, \mathrm{I}_{42} 5^{*} \mathrm{~A}, \mathrm{I} 443^{*} \mathrm{~A}, \mathrm{I} 447 \mathrm{~B}^{*}, \mathrm{I} 503^{*} \mathrm{~A}, \mathrm{I} 548^{*} \mathrm{~A}, \mathrm{I} 55 \mathrm{I}^{*} \mathrm{~B}, \mathrm{I} 56 \mathrm{O}^{*} \mathrm{~A}, \mathrm{I} 567^{*} \mathrm{~J}$, $\mathrm{I} 569^{* *} \mathrm{~A}, \mathrm{I} 777 \mathrm{~B}^{*}, \mathrm{I} 794^{*} \mathrm{~A}, \mathrm{I} 794^{*} \mathrm{~B}, \mathrm{I} 8 \mathrm{O} 5^{*} \mathrm{~B}, \mathrm{I} 8 \mathrm{O} 5^{*} \mathrm{C}, \mathrm{I} 842^{*} \mathrm{D}, \mathrm{I} 849^{*} \mathrm{~A}$ y $\mathrm{I} 95^{*} \mathrm{~A}$.

En la sección de «Historias sobre tontos» [Stories about a Fool, I2OO-I349] he incluido un único número Noia. El $\mathrm{I}_{2}{ }_{4}^{*} \mathrm{~A}$, «O parvo repite as palabras dos pais (amo)». [The Fool Repeats his parents' (Master's) Words], que clasifica tres anécdotas hilarantes protagonizadas por tontos (ingenuos) que dejan en mal lugar a sus familiares o burladores. Sus motivos no coinciden con los de los cuentos clasificados en ATU I2O4 (Fool Keeps Repeating His Instructions).

En la sección «Historias sobre matrimonios» [Stories about Married Couples, I35O-I439] se mantienen los cinco números Noia de CTCGTO: I35I*B, I357*B, $\mathrm{I} 362 \mathrm{C}^{*}, \mathrm{I}_{3} 8 \mathrm{oB}^{*}$ y I380C*. Se trata de historias relacionadas con el sexo, dentro y fuera del matrimonio.

$\mathrm{I} 35 \mathrm{I}^{*} \mathrm{~B}$, «O neno xa ten dentes!» [The child has already teeth!], clasifica tres breves versiones de un cuento muy conocido en Galicia. La esposa que acaba de parir le dice al marido que no tendrán relaciones sexuales hasta que le salgan los dientes a la niña. Pasado un año o poco tiempo después, deseando que el esposo vuelva a su cama, la mujer lo avisa cantando de que la niña ya tiene dientes: «Ai, Tina, tina, tina, xa ten dentes a menina!»; a lo que el marido responde: «Ai, Tina, tana, ti ques i eu non teño gana!».

En el Catálogo tipológico de cuentos murcianos (CTCM), Ángel Hernández registra una versión inédita grabada en Cartagena con el número Noia.

I357*B, «A muller que sabe buscar a vida» [The woman who knows how to sort herself out], es una historia en clave jocosa sobre la pobreza vivida en el matrimonio que induce a las esposas a buscar dinero en la prostitución. En el Catálogo tipolóxico do conto galego están registradas cuatro versiones orales y dos escritas (Colorados $200 \mathrm{O}, \mathrm{n} .^{\circ} 29$ y 30). Mientras el marido, obligado a emigrar para poder vivir, está sin trabajo o gana poco dinero, la esposa consigue un buen salario ejerciendo la prostitución. Cuando el marido regresa y ve el dinero que ha reunido su esposa, le pregunta por su origen. Ella le cuenta cómo lo consigue y el marido la alaba; en una de las versiones, dedica una jaculatoria al órgano sexual: «Bendita sexa a cona, que pola cona comemos, pola cona bebemos, pola cona pagamos a quen debemos e temos cona canta queremos». El Catálogo de contos tradicionais portugueses registra cinco versiones de la misma historia clasificadas con el número Noia.

I362 $\mathrm{C}^{*}$, «O neno negro» [The black child], está clasificado con un número Noia a pesar de registrarse en gallego una única versión. A un matrimonio emigrado en Brasil le nace un bebé negro; la esposa lo justifica ante el marido por el hecho de haberlo dado a criar a una señora negra. Cuando regresan a Galicia, y el padre le 
explica al abuelo la razón de que el niño sea negro, este le responde irónicamente que eso explica también que él sea un cornudo, pues de pequeño fue alimentado con leche de una cabra.

La razón de haber propuesto un número nuevo de clasificación se debió a que conocía la existencia de otras versiones del mismo cuento en castellano, recogidas por Ángel Hernández en Albacete (Cortés Ibáñez I986: IIo-II2, n. I9), Almería (Gómez López I998: 43) y Cartagena (Catálogo tipológico de cuentos murcianos), y una en Sevilla (Agúndez I999, II: 92-94). En esta última, la madre del bebé le dice al marido que el niño es negro porque se lo cambió en el hospital una mujer negra que había en la cama de al lado, con lo cual pierde sentido el motivo final de atribuir los cuernos del padre a la leche de cabra que bebió de pequeño. En el Catálogo de contos tradicionais portugueses de Cardigos y Correia hay registradas otras dos versiones con el número Noia.

El cuento se podría considerar una variante de ATU I362A* The Three Months' Child. Ambos comparten motivos semejantes: un marido ingenuo, relaciones extramatrimoniales de la esposa y engaño con el hijo. Sin embargo, a diferencia de I362 $\mathrm{A}^{*}$, el motivo principal se centra aquí en la respuesta irónica de la abuela o del abuelo del bebé.

I380B*, «Gratis o que outras cobran» [Free what other get paid for], clasifica tres versiones sobre dos esposas que tienen relaciones extramatrimoniales con diferente resultado. Un matrimonio vive de su trabajo con escasos recursos y ve que sus vecinos viven en la abundancia, aparentemente sin trabajar. El marido pobre le pregunta al rico qué hace para vivir tan bien y él le confiesa que su esposa trabaja para él acostándose con otros hombres. Cuando se lo cuenta a su mujer, ella se lamenta de no haber obtenido beneficio económico alguno a pesar de que desde hace tiempo se acuesta con el vecino (panadero, cura). En una de las tres versiones registradas en gallego, la esposa, que había sido monja, le confiesa al marido, convencido de haberse casado con una virgen, que a ella el capellán del convento no le pagaba los servicios prestados.

En el Catálogo de contos tradicionais portugueses (CCTP) hay registradas tres versiones con el número Noia que varían en su primera parte respecto a las gallegas. La esposa no quiere tener relaciones sexuales con el marido y le da dinero para que se las pague a otra. El marido contrata los encuentros sexuales con la vecina, y cuando se lo cuenta a la esposa, esta se indigna y le dice que ella nunca le había cobrado nada al marido de ella.

En este número Noia se clasifica, también, una versión en el Catálogo tipológico de cuentos murcianos que varía en su final. Un hombre muy rico encuentra a un amigo muy pobre. El rico le explica que ha hecho fortuna gracias a que su mujer tiene un querido. El pobre anima a la suya a que coja un amante que los libre de la miseria, y la mujer le confiesa que solo ha podido tener relaciones con el sacristán porque le paga ella.

I380C*, «A muller secreta» [The secret woman], clasifica tres versiones orales y una escrita (Colorados 20oI, n. ${ }^{\circ} 28$ ) de un cuento que se podría calificar de misógino. Un hombre se casa con una mujer fea (coja) convencido de su virginidad, para que no le sea infiel. Después de la boda, en unas versiones, la mujer le confiesa con quién se había acostado y, en otras, admira la habilidad del marido en el encuentro sexual comparándolo con los hombres que le precedieron. La conclusión del cuento podría ser la de que no hay mujeres honestas ni fieles a su marido, por feas 
y defectuosas que sean. Sin embargo, analizado desde otra perspectiva, se puede ver como una muestra de la libertad sexual de que gozaban las mujeres en las antiguas comunidades rurales.

En el apartado «Historias sobre mujeres» [Stories about a Woman I44O-I524] se incluyen cuatro números Noia: $1425^{*} \mathrm{~A}, \mathrm{I} 443^{*} \mathrm{~A}, \mathrm{I} 447 \mathrm{~B}^{*}$ y I5O3*A.

I $425^{*} \mathrm{~A}$, «Rogativas para sandar a vaca» [Prayers to cure the cow], clasifica los dos cuentos grabados en gallego sobre una mujer ingenua que se deja embaucar por un cura (veterinario) lujurioso. Una campesina, al ver que su vaca enferma no se cura con los remedios del veterinario, y se pone cada vez peor, decide llevarla al cura en busca de remedio divino. Este intenta aprovecharse sexualmente de la mujer haciéndole creer que la vaca se curará si ambos dan vueltas desnudos alrededor del animal.

El Catálogo tipológico de cuentos murcianos registra otras dos versiones inéditas con este número, a las que hay que añadir una más también en castellano, recogida en León por Julio Camarena (I99I, II: 75-76, n. ${ }^{\circ} 204$ ). En las tres, el personaje es un veterinario lascivo que le propone el remedio a la mujer, quien, como en el caso de las gallegas, cuando ya está muy excitada, le dice al veterinario: «iAl medio, al medio, aunque la vaca no tenga remedio!».

I443*A, «As mozas recatadas», sobre la habilidad de las mujeres ante el deseo sexual, cambia el título por «A fouce, a cabra, a pola, a ola e as cebolas» [The sickle, the goat, the little chicken, the pot and the onions], que le dan los y las informantes. Una mujer vuelve de la feria (mercado) cargada de cacharros, alimentos y útiles de labranza cuando se encuentra a un vecino que le dice que, si va tan cargada, no podrán enredar. Entonces ella clava la hoz en el suelo, ata allí la cabra, mete la gallina dentro de la olla y la tapa con las cebollas dejando manos y pies completamente disponibles.

Aparte de las cuatro versiones gallegas, se registraron dos en castellano, una murciana clasificada con el número Noia en el CTCM de Hernández y otra leonesa recogida por Camarena (I99I, II: 77, n. ${ }^{\circ}$ 206). Chevalier (I983: I6I) da la referncia de una versión del cuento en dos piezas de teatro de Calderón de la Barca («Peor que estaba», vol. III, BAE, 7: Io6c y «La estatua de Prometeo», III, BAE, I2: 7I4C) y en otra de Lope de Vega («Mirad a quién alabáis», Obras XIII: 46b). Hay otras dos versiones en el Libro de los cuentos (I862) de Rafael Boira y en Museo cómico o Tesoro de los chistes (I863) de Manuel de Palacio y Luis Rivera. Todos estos datos me hacen suponer que el cuento es de origen español. A través de internet he recibido hace pocos meses una versión argentina del mismo cuento, en la que el personaje es un granjero que no sabe cómo colocar la carga que lleva, un caldero, un tarro de pintura, dos gallinas y un ganso, cuando se encuentra a una mujer que le pregunta dónde está cierto lugar. Él le dice que va en esa dirección, pero que con tanta carga no podrá acompañarla, y la mujer le explica cómo llevarlo todo sin problema. De camino, el hombre le comenta que hay un atajo para llegar antes. La mujer aparenta asustarse y le pregunta cómo puede saber que no va a abusar de ella. Él, sorprendido, le responde que, aunque quisiese, tan cargado no podría «achucharla contra un árbol». Entonces la mujer le explica cómo puede colocar todo lo que lleva.

Se trata, pues, de un cuento bien documentado en versiones orales y escritas, en castellano y gallego, por lo menos, desde el siglo XVII. 
I447 $\mathrm{B}^{*}$, «A muller que quería un refresco» [The woman who wanted a soda], es el mejor ejemplo de una forma breve. Se trata de un chiste muy extendido en Galicia, del que no tenemos referencias en otras áreas lingüísticas. Una mujer va a una tienda de pueblo donde se venden productos variados y pide un refresco; mientras el vendedor va a la trastienda, se bebe el líquido amarillo de un recipiente, que era el purgante para un animal, creyendo que era su refresco.

I5O3*A, «Confidencias entre filla e nai sobre a noite de vodas» [Confidences/Secrets between mother and daugther about the weding night], es el único número Noia de la sección «Otras historias sobre mujeres» [Other Stories about Women (I5OO-I524)]. Se recogen aquí dos tipos de anécdotas sobre la primera noche de bodas. En un grupo recojo aquellas en que la madre (u otra persona) oculta en un lugar próximo a la cama de los novios le va preguntando a la hija (o amiga) qué le hace el marido y esta le responde con frases de doble sentido. En otro grupo figuran anécdotas que cuentan que al día siguiente de la boda la madre le pregunta a la hija cómo le ha ido en su primera noche de bodas. La hija le dice que ella y su novio jugaron a un juego muy divertido, y le explica lo que hicieron. Por la noche, la madre intenta hacerlo con su marido y obtiene resultados desastrosos.

El Catálogo de contos tradicionais portugueses registra con el número Noia dos versiones portuguesas del segundo grupo.

En la serie «Historias sobre hombres» [Stories about a Man (I525-I724)] hay cinco números Noia: I548*A, I55I*B, I560*A, I567*J y I569**A.

$\mathrm{I} 548^{*} \mathrm{~A}$, «O fillo listísimo» [The very Clever son], clasifica cuatro versiones orales y una escrita con variantes sobre un muchacho simple al que su padre considera muy listo. Cuando está relatando sus proezas a los vecinos, el hijo lo deja en ridículo al presentarse haciendo o diciendo una estupidez.

$\mathrm{I} 55 \mathrm{I}^{*} \mathrm{~B}$, «Son moscos, non moscas» [They are he flies, not she flies], es otra historia de tontos, esta con final ingenioso. Un tendero engaña a un muchacho diciéndole que le dará un centavo por cada mosca que le lleve. Cuando consigue llenar un bote, el muchacho se lo lleva al tendero. Este echa las moscas sobre el mostrador para contarlas y va diciendo que son moscos, no moscas, por lo que no le da ni un centavo (o le da solo dos o tres). El chico se siente engañado y prepara la venganza. Llena un tarro de excrementos y se lo vende al comerciante como miel.

Este cuento, del que tengo recogidas seis versiones orales y una escrita, está registrado en varias regiones de la península. El CCTP de Cardigos y Correia registra cuatro versiones en Portugal y el CTCM de Hernández tres en la provincia de Murcia. A estas hay que añadir una más en castellano, recogida en León por Julio Camarena (I99I, II: II2, n. ${ }^{\circ}$ 230). En los catálogos portugués y murciano el cuento se clasifica con el número Noia.

I560*A, «Mirar o traballo, mirar o xantar» [Looking on the work, looking on the lunch], clasifica cuatro versiones gallegas de un cuento del que no tengo referencias en otras áreas lingüísticas. Un jornalero al que el amo había mandado que preparase una pequeña porción de monte para plantar regresa a casa del amo a la hora de comer. El amo le pregunta cómo le fue el trabajo, y el jornalero le dice que estuvo mirando por dónde debía empezar a trabajar, pero que todavía no había empezado. El amo pone entonces un mollete de pan sobre la mesa y le da vueltas mirándolo un buen rato hasta que el jornalero le pregunta qué está haciendo. El amo le explica que no sabe por dónde empezarlo y que se quedarán sin comer. 
El tipo ATU I560, Make-Believe Eating; Make-Believe Work, podría clasificar el cuento anterior, pues trata un tema parecido ${ }^{4}$ del que también hay versiones en gallego. Sin embargo, aunque los motivos coincidan, no comer $\rightarrow$ no trabajar y no trabajar $\rightarrow$ no comer, las conclusiones de las historias son inversas. En el I560 un criado finge trabajar y se venga así del amo que había fingido también que comían, mientras que en el número Noia el amo se venga del criado por no trabajar, dejándolo sin comer.

I567*J, «Como se arrefría o caldo» [How to cool the broth?], se clasifica en la subserie de amos y criados. Es un cuento muy extendido en el área gallegoportuguesa. Un joven va a pedir trabajo como criado a una casa y lo aceptan, pero antes de cerrar el trato pregunta cómo enfrían el caldo; al decirle que lo enfrían soplando o con agua se marcha y sigue buscando hasta que encuentra una casa donde enfrían el caldo echándole pan. ${ }^{5}$ El cuento destaca la astucia del criado que, para asegurarse de poder comer algo más que el caldo (comida básica, y a veces única, en las aldeas gallegas hasta mediados del siglo xx), pide pan como condición para trabajar. Este refrán gallego resume la conclusión del cuento: «O caldo sen pan no inferno o dan». Además de las cinco versiones registradas en gallego, hay ocho en portugués en el CCTP de Cardigos y Correia, clasificadas con el número Noia.

En el debate que tuvo lugar tras la presentación de esta comunicación, se me sugirió que el cuento se podría clasificar dentro del tipo misceláneo ATU I567, Stingy Household, ${ }^{6}$ pero después de revisar la sinopsis de las variantes del tipo hemos decidido mantener el número Noia. En ninguna de las versiones gallegas niportuguesas del cuento hay amas (amos) tacañas y en ninguna de las tres sinopsis incluidas en el tipo aparece nada que se aproxime a la historia de enfriar el caldo. La única coincidencia está en que ambos números tratan de amos y criados en relación con la comida. La clasificación con el número Noia de las versiones portuguesas ha unificado los criterios.

I569**A, «O xastre comprace a ama coreña» [The taylor pleases the stingy household], versa sobre amos tacaños y sastres pillos. Es un número misceláneo que cataloga dos clases de anécdotas sobre sastres que no recoge ATU. Tienen en común la aparente complacencia de los sastres ante las demandas del ama, que les pide menos gasto de tela o de hilo y más trabajo, con malos resultados, pues le hacen prendas inservibles o gastan más tiempo en hacerlas.

Una de las versiones gallegas cuenta que el ama le da al sastre un trozo de tela para hacer un gorro, y como le sobra tela para uno, le pregunta si puede hacerle

4. A farmer and his farmhand work in the field. At noon, other who are also working near by stop for a rest and eat. The farmer stops working but tells his farmhand, "We will only act as if we are eating».

When they resume work, the farmhand swings the scythe back and forth without cutting anything. The farmer turns around and asks him what he thinks he is doing. The farmhand says he is acting as if he is working.

5. The servant only stays with the master who, when the servant complains that The broth is hot, gives him bread to cool it down, instead of asking him to blow it cool.

6. Al revisar las versiones españolas incluidas en el tipo ATU I567 buscando versiones del cuento gallego-portugués, pude comprobar que ni los cuentos citados de Aurelio Espinosa hijo, núms. 347-348 de Cuentos de Castilla y León (I988), ni el n. ${ }^{\circ} 224$ de Julio Camarena de Cuentos tradicionales de León, II (I99I) se aproximan a la descripción del tipo ni a los motivos. Me pregunto si los tipos misceláneos valen para clasificar cuentos con protagonistas de oficios semejantes, aunque no coincidan los motivos. 
otro, y va pidiéndole más hasta llegar a cinco gorros, uno para cada hijo. El sastre accede y le hace cinco gorritos que solo se pueden poner en los dedos.

Esta historia coincide con las dos versiones murcianas registradas en el CTCM y aparece en el segundo capítulo del Quijote (II-45).

En la sección Jokes about Clergymen and Religious Figures (I725-I849) se mantienen los siete números Noia: $\mathrm{I}_{777 \mathrm{~B}^{*}}$, I794*A, I794*B, I805*B, I80 ${ }^{*} \mathrm{C}, \mathrm{I} 842^{*} \mathrm{D}$ y I $849^{*} \mathrm{~A}$.

$\mathrm{I}_{777} \mathrm{~B}^{*}$, «Xa te entendo, xa te entendo» [I understand you, I understand you!], es una simpática anécdota entre un cura y un sacristán. Este recrimina al sacerdote por andar rondándole la esposa con dos palabras: «¡Señor cura... señor cura!», a las que el sacerdote le responde con la frase del título, «Xa te entendo».

El cuento puede considerarse una variante de I777A*, «I can't Hear You» («No se oye nada»), y por tanto podría clasificarse con este subtítulo, pero, dado que tenemos registradas cinco versiones en gallego de esa anécdota tiene entidad suficiente para disponer de un número propio de clasificación.

I794*A, «Sacristán persuasivo» [The Persuasive Sexton], narra la anécdota de un sacristán (un muchacho) que consigue lo que quiere a fuerza de insistir una y otra vez. Un cura harto de oírle pedir su petaca (un reloj) a su sacristán, acaba dándosela. Cuando una muchacha le dice en confesión que el sacristán quiere tener relaciones sexuales con ella, el cura le dice que se dé por vencida, que es imposible resistirse a su persuasión.

En gallego hay registradas cuatro versiones orales, y en todas aparece el personaje del sacristán. En la registrada por José Luis Agúndez (I999, II: 264-265) en Sevilla se trata de un muchacho que va a recoger al cura a la estación y al verle la petaca se la pide con insistencia. En los comentarios de la historia, Agúndez da la referencia de tres versiones escritas del cuento en antologías del siglo XIX y del primer tercio del siglo xx: «La constancia», en Una docena de cuentos de Narciso Campillo (I878: 37-54); «Chá... Chara», en Del oído a la pluma de Rodríguez Marín (I908: I7-25), y «Pobre porfiado», en Obras incompletas del El Conde de las Navas (I929: 60-69).

I794* $\mathrm{B}$, «Mollar o pan en aceite» [Dip Bread in Oil], cuenta que un párroco recrimina al sacristán (monaguillo) por haber mojado en varias ocasiones el pan en el aceite de las lamparitas de la iglesia. El sacristán le pregunta quién le dijo que había sido él, y el cura le responde que ha sido la Virgen (el Niño Jesús o un santo). Cuando pretende volver a mojar el pan, el sacristán, en unas versiones, le tapa la cara con un trapo a la imagen; en otras, dirigiéndose enfadado a ella, le dice que va a comer el pan seco.

En gallego, tenemos registradas cuatro versiones en el CTCGTO. Cardigos y Correia, en el CCTP, registran diez versiones en portugués con las variantes respecto a las gallegas de sustituir el personaje del sacristán por un chico negro (criado) y porque en ellas el cura habla detrás de la imagen para censurar al chico.

$\mathrm{I} 8 \mathrm{O} 5 * \mathrm{~B}$, O penitente recibe información do confesor» [The penitent gets information in Confessional], cuenta que un confesor para animar al penitente a decirle dónde cometió el pecado (robo, adulterio...) les va enumerando lugares donde pudo haber sido. El penitente, bien informado de dónde encontrar buena fruta o de los nombres de las mujeres que le pueden interesar, sale contento de la iglesia a pesar de no recibir la absolución. 
En el CTCGTO se registran dos versiones del cuento en gallego, y hay una en portugués (CCTP) clasificada con el número Noia. El cuento es una variante del número de Cardigos $1805^{*} \mathrm{~A}$, «O padre aprende truques no confessionário» [The Priest Learns trikcs in Confessional], con el mismo tema. La diferencia con el número Noia estriba en que en las versiones clasificadas con el número Cardigos es el sacerdote quien recibe información del penitente al confesar este su pecado.

I $805{ }^{*} \mathrm{C}$, «Os clientes pagan menos» [Customers pay less], es un chiste basado en un malentendido sobre un hombre que ha encontrado una cantidad de dinero y se va a confesar para saber qué hacer con él. Como no puede devolverlo al dueño porque no sabe quién es, el cura le dice que le dé una moneda de cinco duros a la primera persona que encuentre en el camino. Es una muchacha la primera que aparece, y él le ofrece los cinco duros, pero ella los rechaza porque dice que cobra más por sus servicios. El hombre le replica que le da la cantidad mandada por el cura, y ella le dice que a los clientes les cobra menos.

En gallego hay registradas tres versiones orales y una escrita, y el CCTP de Cardigos y Correia registra dos en portugués. En estas, el dinero que el home debe dar es en penitencia por sus pecados, no por haberlo encontrado. El CTCM de Hernández registra dos versiones murcianas del mismo cuento, una en castellano y otra en catalán, con una variante sobre el motivo inicial de las portuguesas, un blasfemo tiene que dar una cantidad de dinero en penitencia cada vez que diga una blasfemia. Julio Camarena (I99I, II: I57-I58, núms. 263-264) recoge dos versiones leonesas en castellano.

$\mathrm{I} 842^{*} \mathrm{D}$, «O testamento do cura» [The priest's testament], es un breve chiste de un sacerdote (un hombre) muy pobre que, próximo a la muerte y ante la insistencia de sus criadas (parientas) para que haga el testamento, les reparte su cuerpo (los órganos sexuales), el alma y los animales de la casa.

El CCTP de Cardigos y Correia registra una versión en la que un hombre deja escrito un texto en el que reparte sus órganos sexuales entre la madre y la tía, coincidente con una de las versiones gallegas recogida en Palas (Lugo). El CTCM de Hernández clasifica también con este número tres versiones del cuento con variantes respecto a las versiones gallego-portuguesas. Un indigente se hace pasar por rico y va a casa del cura en busca de alguien a quien dejarle su herencia. Cuando se muere descubren que solo reparte su cuerpo. En el área lingüística del castellano se registran otras cinco versiones, recogidas en León (Camarena I99I, II: I77, n. ${ }^{\circ}$ 285), Albacete (López Megías 200o: 224), Badajoz (Rodríguez Pastor 200I: I50.6) -en los dos últimos casos con un gitano como personaje-; Burgos (Rubio et al. 2002: 154) y Logroño (Asensio García 2002: 277-278). En todas estas antologías el cuento aparece sin catalogar. Elías Rubio, José Manuel Pedrosa y César Javier Palacios, autores de Cuentos burgaleses de tradición oral (2002), proponen clasificar el cuento dentro del tipo misceláneo ATU I870 [Anecdotes about Various Religions and Sects], ya que en su versión el personaje es un clérigo. Los catálogos portugués y murciano han clasificado sus cuentos con el número Noia.

I849*A, «Palabras sagradas e blasfemas para facer andar a burra (cabalo)» [Sacred and blasphemous words to make the ass (Jenny) walk], clasifica anécdotas sobre un eclesiástico (cura, obispo) que va montado en una burra (un caballo) que se detiene. En unas versiones, solo vuelve a andar si oye una blasfemia; en otras, si oye rezar o decir una jaculatoria. 
Además de las cinco versiones gallegas registradas en el CTCGTO, hay dos murcianas en el CTCM de Hernández y una burgalesa recogida por Elías Rubio y otros (2002, I27-I28) protagonizada por un carretero que estimula su montura echando maldiciones.

En la sección miscelánea final del apartado «Chistes y anécdotas» [«okes and Anecdotes»], que lleva el título —en mi opinión- poco adecuado de Tall Tales (I875-I999), está incluido el último número Noia del apartado.

I95 $\mathrm{I}^{*} \mathrm{~A}$, «Pedir axuda aos santos para non traballar» [To Ask the saints for help to avoid working], cuenta una historia semejante y en el mismo escenario que la clasificada en ATU I476, Prayer to Christ Child's Mother (Boggs I476B*). La diferencia está en los personajes y en los favores solicitados a los santos (Virgen). En el I476 son mujeres (madre o hija) quienes piden un marido a la Virgen o a san Antonio, mientras que el número Noia clasifica historias que tratan de un hombre vago que va a la iglesia a pedirle ayuda a san Antonio para que le toque la lotería y no tener que trabajar. La segunda parte coincide en los dos números, pero no en los diálogos entre los personajes. En el I95I*A el sacristán, colocándose detrás de la imagen, se burla del vago o le aconseja que trabaje, diciéndole «-Dobra, Xan, dobra!», es decir, «baja el lomo y ponte a trabajar». El hombre, creyendo que la voz procede del santo, le responde con alguna frase graciosa.

El CTCM de Hernández registra también con el número Noia una versión murciana del cuento («El cuento de Mangas Verdes»), que tiene alguna variante respecto a las gallegas. El vago le pide a una imagen de Cristo que le diga dónde puede encontrar un tesoro para no tener que trabajar; y su hermano, oculto detrás de la imagen, le dice «¡doble, doble!», que es interpretado por el vago como que debe doblar la ofrenda de aceite al Cristo.

Dado que las tres versiones registradas en Galicia, además de la murciana, dan cierta identidad al cuento, me pareció importante no clasificarlas en ATU I476 como una simple variante de ese tipo. Considero que la presencia de personajes masculinos aproxima más este cuento a los clasificados en la sección de «Historias sobre un hombre».

Los ejemplos presentados en los números Noia y los numerosos cuentos del apartado «Chistes y anécdotas» que todavía están sin por catalogar en las antologías españolas de las distintas áreas lingüísticas de la península dan cuenta de la necesidad de que un equipo de catalogadores y catalogadoras acometa el inmenso trabajo de clasificación pendiente. Ese trabajo debería partir del iniciado por Julio Camarena, que se guarda en el Seminario Menéndez Pidal de la Universidad de Alcalá de Henares, así como de las propuestas de clasificación que Carlos González Sanz, Isabel Cardigos y Paulo Correia o yo misma hemos realizado en nuestros catálogos regionales. 


\section{Referencias bibliográficas}

\subsection{Catálogos de cuentos orales}

AARne, Antti (I9Io): Verzeichnis der Märchentypen. Folklore Fellows' Communications 3. Helsinki: Suomalainen Tiedeakatemia.

[AT] Aarne, Antti; Stith Thompson (I928): The Types of the Folktale. A Classification and Bibliography. Folklore Fellows' Communications I84. Helsinki: Suomalainen Tiedeakatemia. [Primera revisión I96I, segunda I98I.]

- (I995): Los tipos del cuento folklórico. Una clasificación. Trad. española de F. Peñalosa. Helsinki: Suomalainen Tiedeakatemia.

[ATU] UTHER, Hans-Jörg (2004): The Types of International Folktales. A Classification and Bibliography. 3 vols. Folklore Fellows' Comunications 284-285-286. Helsinki: Suomalainen Tiedeakatemia.

BoggS, Ralph S. (I930): Index of Spanish Folktales. Folklore Fellows' Comunications 9o. Helsinki: Suomalainen Tiedeakatemia. [Segunda edición, I993.]

CAMARena, Julio; Maxime Chevalier (I995): Catálogo tipológico del cuento folklórico español. Vol. I, Cuentos maravillosos. Madrid: Gredos.

- (I997): Catálogo tipológico del cuento folklórico español. Vol. II, Cuentos de animales. Madrid: Gredos.

- (2003a): Catálogo tipológico del cuento folklórico español. Vol. III, Cuentos religiosos. Alcalá de Henares: Centro de Estudios Cervantinos.

- (2003b): Catálogo tipológico del cuento folklórico español. Vol. IV, Cuentos-novela. Alcalá de Henares: Centro de Estudios Cervantinos.

CARDigos, Isabel (2006): Catalogue of Portuguese Folktales. Folklore Fellows' Communications 29I. Helsinki: Suomalainen Tiedeakatemia.

[CCTP] CARDigos, Isabel; Paulo CORREIA: «Catálogo dos contos tradicionais portugueses», com as versões análogas dos países lusófonos. [Inédito, con nuevos tipos.]

[CG I996] GonzÁLEz SANZ, Carlos (I996): Catálogo tipológico de cuentos folclóricos aragoneses. Zaragoza: Instituto Aragonés de Antropología.

[CG I998] GonzÁlez SANZ, Carlos (I998): «Revisión del Catálogo tipológico de cuentos folklóricos aragoneses: Correcciones y ampliación». Temas de antropología aragonesa, 8 (1998): 7-60.

[CTCGTO] NoiA, Camiño (20Io): Catálogo tipolóxico do conto galego de tradición oral. Vigo: Servizo de publicacións de Universidade de Vigo.

[CTCM] HERnÁndez Fernández, Ángel (20I3): Catálogo Tipológico del Cuento Folclórico en Murcia. Serie Literatura, Etnografía, Antropología. Alcalá de Henares: El Jardín de la Voz. <http://www.eljardindelavoz.com/libros/catalogomurciano.pdf $>$ [fecha de consulta: noviembre de 20I3]

UTHER (2004): ver ATU. 


\subsection{Colecciones de cuentos}

Agúndez GARCíA, José Luis (I999): Cuentos populares sevillanos (en la tradición oral y en la literatura. Tomo I-II. Sevilla: Fundación Machado.

ASENSIO GARCíA, Javier (2002): Cuentos riojanos de tradición oral. Logroño: Gobierno de La Rioja.

[Colorados 2OoI] Cuba, Xoán R.; Antonio Reigosa; Xosé Miranda (200i): Contos colorados. Vigo: Xerais.

BArroso Gutiérrez, Félix (2005): «La figura juglaresca del tío Goyo, un arquetipo urbano». Revista de Folklore n. ${ }^{\circ} 292$ (2005): II4-I3O.

BoIRA, Rafael (I862): Libro de los cuentos. Tres tomos. Madrid: Imprenta M. Arcas y Sánchez.

CAMARENA LAUCIRICA, Julio (I99I): Cuentos tradicionales de León. 2 vols. Madrid: Seminario Menéndez Pidal/Universidad Complutense/Diputación Provincial de León.

CAmpillo, Narciso (I878): Una docena de cuentos. Madrid: Oficinas de la Ilustración española.

Chascarrillos andaluces coleccionados y narrador por un Andaluz. Sevilla, I9OI.

CheVAlier, Maxime (I975): Cuentecillos tradicionales en la España del Siglo de Oro. Madrid: Gredos.

- (I983): Cuentos folklóricos españoles del Siglo de Oro. Barcelona: Crítica.

CONDE DE LAS NAVAS (I929): Obras Incompletas. Cuentos y chascarrillos propios y ajenos. Tipografía Católica de A.F. (Juan Walberto López Valdemoro y de las Navas).

CORTÉs IbÁÑEZ, Emilia (I986): Zahora. Revista de tradiciones populares n. ${ }^{\circ}$ 9. Cuentos de la zona montañosa de la provincia de Albacete. Albacete: Diputación Provincial.

EsPINOSA, Aurelio, hijo (I987-I988): Cuentos populares de Castilla y León. Vols. I-II. Madrid: CSIC.

Frutos BAEZA, José (I897): De mi tierra: romances, bandos, cuentos y juegos representados en la huerta de Murcia. Murcia: Tipografía de Antonio de Echenique.

Gómez López, Nieves (I998): Cuentos de transmisión oral del Poniente almeriense. Roquetas de Mar: Ayuntamiento.

GómEz López, Nieves et alii (2007): Literatura de tradición oral del levante almeriense. Almería: Grupo de Desarrollo Rural Levante almeriense.

PAlacio, Manuel de; Luis Rivera (I863): Museo cómico o Tesoro de los chistes. Madrid: Librería de Miguel Guijarro.

Rodríguez Marín, Francisco (I908): Del oído a la pluma. Madrid: Biblioteca patria.

RODRÍGUEz PASTOR, Juan (2OOI): Cuentos extremeños obscenos y anticlericales. Badajoz: Diputación.

Rubio Marcos, Elías; José Manuel Pedrosa; César Javier PAlacios (2002): Cuentos burgaleses de tradición oral (Teoría, etnotextos y comparativismo). Burgos: edición de autor. 